\title{
EDITORIAL
}

\section{Disminución de la adherencia, un efecto colateral de la pandemia}

\author{
Ares Vergoñós \\ Farmacéutica comunitaria en Lleida. Coautora de la guía ADHE+ de adherencia terapéutica.
}

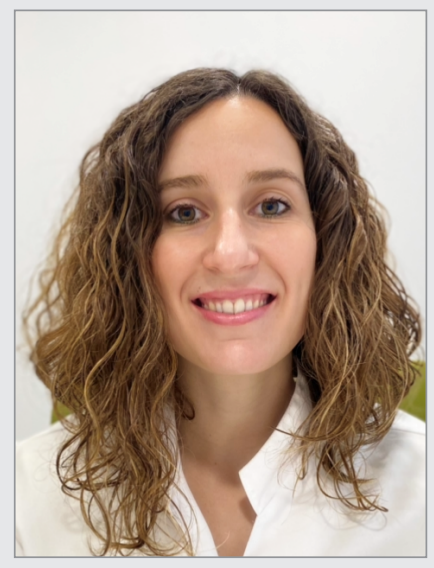

Ares Vergoñós

\section{PALABRAS CLAVE}

Adherencia terapéutica, farmacia comunitaria

\section{ABREVIATURAS}

RUM: revisión del uso de la medicación

SFT: seguimiento

farmacoterapéutico

SPD: sistemas personalizados de dosificación

\section{KEYWORDS}

Therapeutic adherence, Community Pharmacies
Entró la COVID-19 sin pedir permiso, pero eso no hizo que las patologías crónicas se fueran. Al contrario, han seguido ahí y estos pacientes crónicos (que son muchos) han necesitado y siguen necesitando la misma atención o seguimiento. Durante el estado de alarma la atención primaria y la especializada estuvieron saturadas, derivando en consultorios y ambulatorios cerrados, analíticas e intervenciones pospuestas y quedando las patologías crónicas en un segundo plano.

Sin embargo, las 22.102 farmacias en todo el país, cercanas y accesibles al paciente, siguieron abiertas, al lado de los pacientes desde el primer día y nos dimos cuenta de algo: si ya antes de la COVID-19 solo el $50 \%$ de los pacientes eran adherentes a su medicación, esta nueva situación excepcional hizo temblar aún más de lo que ya lo estaba el problema de la adherencia al tratamiento.

La falta de adherencia es un problema complejo, ya que es debido a múltiples causas: relacionadas con el paciente (sexo, edad, nivel de estudios, número de medicamentos, hábito tabáquico, ejercicio físico), con la terapia (presencia de efectos adversos, aceptación de los tratamientos prescritos...), con el estado de la enfermedad (ausencia o presencia de síntomas, severidad de la enfermedad...), con los factores socioeconómicos (apoyo familiar, situación laboral...) o con la relación con el sistema sanitario.

Durante los momentos más críticos de la pandemia, la falta de adherencia además se agravó por varias razones como, por ejemplo, que algunos pacientes no recogían su medicación por miedo al contagio del virus, o bien la recogían familiares, algunos de los cuales no estaban familiarizados con sus tratamientos.

Y a su vez, el incumplimiento terapéutico supone un mayor número de ingresos hospitalarios, la instauración de nuevos medicamentos que no hubieran sido necesarios y un aumento de la morbilidad y mortalidad, conduciendo a una mayor carga para el sistema de salud, acentuándose durante la COVID-19.

En el presente número se publica un excelente trabajo realizado en farmacias de Orense donde demuestra que en la farmacia comunitaria se puede hacer mucho para mejorar la adherencia. Podemos abordar la adherencia a los tratamientos con herramientas como el test de Haynes-Sackett o el de Morisky-Green de ocho ítems (MMAS-8) para saber si un paciente es o no adherente e ir tirando del hilo. ¿Cómo? Una vez detectado si el paciente es o no adherente al tratamiento, podemos saber a qué perfil de paciente nos enfrentamos (confundidos, desconfiados, que banalizan) y cuál será la mejor estrategia o intervención en la mejora de la adherencia. Tal vez ¿una revisión del uso de la medicación (RUM)? o ¿un sistema personalizado de dosificación (SPD)? o ¿un seguimiento farmacoterapéutico (SFT)? Todo esto está muy bien explicado en la guía $\mathrm{ADHe}+$, que SEFAC público en 2017 (1). 
Esto nos lleva a una reflexión: todos los ámbitos (los distintos profesionales sanitarios, entorno del paciente, trabajadores sociales...) deberiamos trabajar de forma estructurada y coordinada para resolver este problema complejo de salud pública. De otro modo, si cada ámbito sigue actuando de forma independiente en lugar de trabajar todos con un protocolo estandarizado, cuando uno flaqueé (por ejemplo, debido a la COVID-19) será más difícil mantener una situación de control.

Adherencia no es solo la toma de medicación, sino también la implicación y el compromiso del paciente con su enfermedad, con su tratamiento y con los profesionales sanitarios que lo rodean. Desde que llegó la COVID-19 el problema sigue siendo el mismo, pero los obstáculos cada vez son mayores. ¿No es ya la hora de implantar un protocolo donde toda la red sociosanitaria esté unida e implicada de una vez por todas?

\section{REFERENCIAS BIBLIOGRÁFICAS}

1. Prats Mas R, García Zaragoza E, Gil Girbau M, Murillo Fernández MD, Vázquez Valcuende J, Vergoñós Tomàs A. Dispensación, adherencia y uso adecuado del tratamiento: guía práctica para el farmacéutico comunitario. [Monografia en Internet] Madrid. Sociedad Española de Farmacia Clínica, Familiar y Comunitaria. 2017. [último acceso 10/06/2021] Disponible en: https://www.sefac.org/sites/default/ files/2017-11/Adherencia_0.pdf 